\title{
Utilization of protozoal selenium in young goats
}

\author{
T. Fujihara ${ }^{1,3}$, T. Imamura ${ }^{1}$ and E.A. Orden ${ }^{2}$ \\ ${ }^{1}$ Faculty of Life and Environmental Science, Shimane University \\ Matsue-shi 690-8504, Japan \\ ${ }^{2}$ Small Ruminant Centre, Central Luzon State University \\ Nueva Ecija 3120, Philippines
}

\begin{abstract}
A balance trial was conducted to determine the availability and utilization of protozoal-selenium (Se) for young goats. Protozoal-Se was prepared from rumen fluid of a sheep supplemented with $0.4 \mathrm{mg}$ inorganic Se (sodium selenite). A milk replacer diet without Se was supplemented with either $0.1 \mathrm{mg} / \mathrm{kg}$ diet of protozoal-Se or inorganic Se or no Se (control). The utilization coefficient of Se did not vary significantly $(\mathrm{P}>0.05)$ between kids supplemented with protozoal-Se and selenite. Blood Se level was similar in the Se supplemented groups. Results suggest that protozoa-Se can be absorbed in the lower gut and efficiently utilized by young goats in similar manner as selenite.
\end{abstract}

KEY WORDS: selenium utilization, protozoal selenium, young goats, bottle feeding

\section{INTRODUCTION}

Previous findings have shown that rumen microbes are capable of incorporating Se into their cell (Hidiroglou et al., 1968; Hudman and Glenn, 1984). Researchers surmised that this could be the reason for the low net absorption of Se among ruminants. The reduction-reactions happening in the rumen could also contribute to the low turnover of Se (Cousins and Cairney, 1961; Peterson and Spedding, 1963; Harrison and Conrad, 1984). Although there was an increasing evidence of Se trapping by microbial rumen population, our earlier study showed that bacterial-Se collected from the rumen of wethers was not fully available for absorption in the intestine of mice (Serra et al., 1997). If bacterial-Se had low bioavailability, other rumen microbes that can incorporate Se into their cell could provide a better influx of Se in the lower gut. In the present study, the availability of protozoal-Se obtained from the rumen of sheep was determined in a balance experiment using young goats.

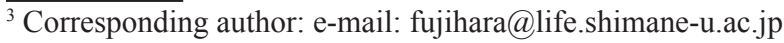




\section{MATERIAL AND METHODS}

\section{Animals, treatments and experimental procedure}

The protozoal Se was obtained from rumen fluid of sheep fed with 3 parts timothy hay +2 parts concentrate that provided $0.4 \mathrm{MJ} / \mathrm{BW}^{0.75} / \mathrm{d}$, and supplemented with $0.4 \mathrm{mg}$ inorganic Se (sodium selenite) per kg diet. The experiment involved four ( 2 males and 2 females) 5 -week-old kids in a switchback design, allowing 7 -day adjustment and 8-day collection period. Aside from the daily milk replacer diet given to the control group $(0.057 \mathrm{mg} \mathrm{Se} / \mathrm{kg}$ dry matter), the treated groups were supplemented with $0.1 \mathrm{mg} / \mathrm{kg}$ diet each of protozoal or inorganic Se. During the collection period, total faecal and urine voided out were collected. About 7 $\mathrm{ml}$ of blood was also collected daily through jugular vein prior to the 9 'clock morning feeding.

\section{Analytical methods}

The Se content of protozoa, faeces, urine and blood were analysed by the method presented earlier (Serra et al., 1994). Data were analysed by one-way ANOVA, and a mean comparison by Fisher' PLSD.

\section{RESULTS AND DISCUSSION}

\section{Protozoal-Se preparation}

The collected rumen-protozoa contained $0.52 \mathrm{mg} \mathrm{Se} / \mathrm{kg}$ of protozoal dry matter, almost the same value as that reported by Serra et al. (1997) using sheep supplemented with sodium selenite at the rate of $0.2 \mathrm{mg} / \mathrm{kg}$ diet. Apparently, about $0.5 \mathrm{mg} \mathrm{Se} / \mathrm{kg}$ of protozoal dry matter is a maximum limit of Se trapping into rumen-protozoa.

\section{Se balance}

Selenium intake varied relative to the changes in feed consumption and weight gain. Although protozoal-Se intake tended to be highest $(\mathrm{P}>0.05)$, there was no significant difference observed in the Se intake between the supplemented groups. Likewise, the ratio of absorbed and retained Se with that of the intake expressed, as coefficient of utilization did not vary significantly $(\mathrm{P}>0.05)$. It is interesting to note that there was a distinct pattern in the route of Se excretion among the animals, as faecal Se appeared to be higher $(\mathrm{P}>0.05)$, when kids were fed protozoal-Se while the selenite feeding resulted to greater urinary Se excretion. Apparently, inorganic Se could provide higher amount of absorbed Se as a proportion of intake (Serra et al., 1994) while protozoal-Se had greater retention. However, the similar utilization coefficient of the treated groups suggests that protozoal-Se could enhance influx of bio-available cellular Se into the lower gut of ruminants. The results suggest that seleno-protein incorporated in rumen protozoa could be 
a potential source of Se among ruminants with similar bioavailability compared with inorganic-Se (Butler and Peterson, 1961). Moreover, the results indicated (protozoal versus bacterial was not measured in this experiment) that protozoal-Se is more available than bacterial-Se (Serra et al., 1997).

\section{Blood Se concentrations}

The blood Se concentrations of kids fed with protozoal-Se and selenite were not significantly different $(\mathrm{P}>0.05)$. This parameter was used, as a gauge to determine whether various form of Se could be made available and transported through the blood stream. It also served as a tool in identifying toxicity level or deficiency symptoms (Gerloff, 1992). Apparently, both protozoa and selenite provided adequate blood Se concentration. Moreover, the absence of sub-clinical signs of Se deficiency suggests that the observed blood Se concentration was within the normal range.

\section{CONCLUSIONS}

The insignificant differences in the utilization coefficient of Se among young goats suggests that protozoa-Se is absorbed in lower gut and can be efficiently utilized by the animal in a similar manner with that of sodium selenite. There were even indications of higher availability of protozoal-Se compared to selenite. This is contrary to general observation that utilization rate of microbial Se is lower compared to inorganic Se sources. With the contradicting findings regarding the bioavailability of microbial-Se, there is a need to conduct confirmatory experiments.

\section{REFERENCES}

Butler G.W., Peterson P.J., 1961. Aspects of the faecal excretion of selenium by sheep. N. Z. J. Agr. Res. 4, 484-491

Gerloff B.J., 1992. Effect of selenium supplementation on dairy cattle. J. Anim. Sci. 70, 3934-3940

Cousins F.B., Cairney I. M., 1961. Some aspects of selenium metabolism in sheep. Aust. J. Agr. Res. $12,927-943$

Harrison J.H., Conrad H.R., 1984. Effect of selenium intake on selenium utilization by the nonlactating cows. J. Dairy Sci. 67, 219-223

Hidiroglou M., Heaney D.P., Jenkins K.J., 1968. Metabolism of inorganic selenium in rumen bacteria. Can. J. Physiol. Pharmacol. 46, 229-232

Hudman J.F., Glenn A.R., 1984. Selenite uptake and incorporation by Selenomonas ruminantium. Arch. Microbial. 140, 252-256

Peterson P.J., Spedding D.J., 1963. The excretion by sheep of ${ }^{75}$ selenium incorporated into red clover (Trifolium pratense L.) the chemical nature of the excreted selenium and its uptake by three plants species. N.Z.J. Agr. Res. 6, 13-23 
Serra A.B., Nakamura K., Matsui T., Harumoto T., Fujihara T., 1994. Inorganic selenium for sheep. I. Selenium balance and selenium levels in the different ruminal fluid fractions. Asian-Austr. J. Anim. Sci. 7, 83-89

Serra A.B., Serra S.D., Fujihara T., 1996. Influence of dietary protein on the apparent absorption and retention of selenium in sheep. Asian-Austr. J. Anim. Sci. 9, 551-556

Serra A.B., Serra S.D., Shinchi K., Fujihara T., 1997. Bioavailability of rumen bacterial selenium in mice using tissue uptake technique. Biol. Trace Elem. Res. 58, 255-261 